\title{
Strategic Judgment Proofing
}

\section{Citation}

Yeon-Koo Che \& Kathryn E. Spier, Strategic Judgment Proofing, 39 RAND J. Econ. 926 (2008).

\section{Published Version}

http://onlinelibrary.wiley.com/doi/10.1111/j.1756-2171.2008.00044.x/pdf

\section{Permanent link}

http://nrs.harvard.edu/urn-3:HUL.InstRepos:11225152

\section{Terms of Use}

This article was downloaded from Harvard University's DASH repository, and is made available under the terms and conditions applicable to Open Access Policy Articles, as set forth at http:// nrs.harvard.edu/urn-3:HUL.InstRepos:dash.current.terms-of-use\#OAP

\section{Share Your Story}

The Harvard community has made this article openly available.

Please share how this access benefits you. Submit a story.

\section{Accessibility}




\title{
Strategic judgment proofing
}

\author{
Yeon-Koo Che* \\ and \\ Kathryn E. Spier**
}

A liquidity-constrained entrepreneur raises capital to finance a business activity that may harm bystanders. The entrepreneur raises senior (secured) debt to shield assets from the tort victims in bankruptcy. For a fixed level of borrowing, senior debt creates better incentives for precaution taking than either junior debt or outside equity. The entrepreneur's level of borrowing is, however, socially excessive. Giving tort victims priority over senior debtholders in bankruptcy prevents overleveraging but leads to suboptimal incentives. Lender liability exacerbates the incentive problem even further. A limited seniority rule dominates these alternatives. Shareholder liability, mandatory liability insurance, and punitive damages are also discussed.

\section{Introduction}

- There was a striking $41 \%$ rise in the number of taxi and livery accidents in New York City in the 1990s. As described in the New York Times, many of the victims - often bystanders on the sidewalk - found themselves unable to collect their awards after receiving favorable judgments at trial. There were several reasons for this. First, most of New York City's 12,000 taxi cabs were minimally insured. Second, the taxi industry is organized in such a way as to make taxi medallions - worth about $\$ 275,000$ each — unreachable by the victims. The owners of the medallions often use them as collateral for loans, so that "even when the rare victim tries to seize a medallion in court, it is common to find that the owner has attached so much debt to it that

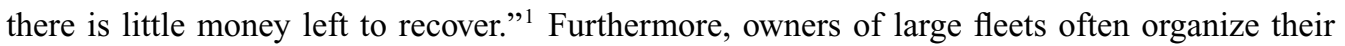
operations into collections of much smaller taxi companies owning just two or three medallions, thereby protecting their assets from liability. In the words of Pam Liapakis, former president of the New York State Trial Lawyers Association, "When one owner can own 100 cars in different

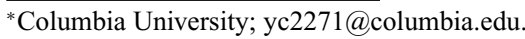

**Harvard University; kspier@law.harvard.edu.

The authors thank Barry Adler, Ian Ayres, Lucian Bebchuk, Patrick Bolton, Albert Choi, Jim Dana, Allen Ferrell, Fernando Gomez, Oliver Hart, Kazumi Hori, Daniel Klerman, Reinier Kraakman, Yair Listokin, Paul Mahoney, Mark Ramseyer, Chris Sanchirico, Alan Schwartz, James Spindler, Eric Talley, Abe Wickelgren, Justin Wolfers, many seminar participants, and the editor and referees for helpful comments. They acknowledge the Shoemaker Fellowship and Searle Fund for their respective financial support.

${ }^{1}$ Drew and Newman (1998). Much of this debt existed before the accidents took place. On some occasions, however, taxi owners engaged in additional borrowing following the court's findings of liability. This practice, illegal, further frustrates the victim's attempts to collect. 
corporations, and then mortgage them to protect his assets from accident victims, that's wrong. ... The purpose of the corporate law is being subverted."

These concerns are hardly unique to the taxi industry. In light of increasing malpractice premiums, many physicians are protecting their assets with limited liability partnerships, irrevocable trusts, and offshore trusts, sometimes forgoing malpractice insurance altogether. Similar strategies are used by accountants, corporate board members, and even lawyers. In a 2003 survey of individuals with personal assets exceeding \$1 million, 35\% had adopted an asset protection plan, up from $17 \%$ in $2000 .^{2}$ Asset protection strategies are not restricted to small businesses. ${ }^{3}$ Following an oil spill in the Gulf of Mexico, French oil company Elf Aquitaine decided to relinquish ownership of its oil prior to shipping it to refineries in the United States (Sullivan, 1990). More generally, large corporations have an incentive to spin off their most hazardous activities into separate units with limited financial assets. ${ }^{4}$ Indeed, Ringleb and Wiggins (1990) attributed a 20\% increase in the number of small corporations between 1967 and 1980 to the outsourcing of risky activities by large corporations to small firms. ${ }^{5}$ Large companies can also issue secured debt based on their physical assets, and then use the cash received to buy back equity or pay dividends to existing shareholders (LoPucki, 1996). ${ }^{6}$ Furthermore, companies can issue so-called Bowie bonds to securitize future cash flows, thus making them unavailable to tort victims. $^{7}$

This article is concerned with "strategic judgment proofing," the deliberate strategies used by firms to shield their assets from future accident victims. Although this issue has been discussed in the legal literature and to some extent in the empirical economics literature, very little theoretical work has been done. Specifically, we consider a liquidity-constrained entrepreneur (the injurer) who raises capital to finance a risky activity that may harm others. The entrepreneur can judgment proof himself through both the method of financing (namely through secured senior debt) and the level of financing. These two tactics potentially impose costs on third parties (the tort victims) and affect the entrepreneur's incentives to improve the safety of his operations. We consider the social desirability of the entrepreneur's judgment-proofing strategies and the effectiveness of several proposed remedies.

Taking the level of borrowing as fixed, we first show that the entrepreneur would choose to finance the risky activity with secured senior debt. Secured senior debt enjoys the highest priority in bankruptcy, and can therefore be used to shield assets from tort victims. Interestingly, this form of strategic judgment proofing enhances social welfare. Taking the level of outside financing as fixed, senior debt creates the best incentives for the entrepreneur to take precautions to reduce the harm to the victims. The reasoning is as follows. The secured senior debtholders face a lower risk of nonrepayment than the holders of junior claims and, as a consequence, require a lower interest rate. This lower interest rate makes bankruptcy less likely, leading the entrepreneur to better internalize the social harm from the risky activity. ${ }^{8}$

${ }^{2}$ Silverman (2003). The survey was conducted by Prince \& Associates, a Connecticut market research and consulting firm. See also Mandell (1999).

${ }^{3}$ See also LoPucki (1996), Gilles (2006), and Hansmann and Kraakman (1991).

${ }^{4}$ Walkovsky v. Carlton, 276 2d 585 (2d Cir. 1966), is a famous veil-piercing case. A cab company had shielded themselves from liability by incorporating each cab as its own corporation. The court refused to pierce the veil on account of undercapitalization alone.

${ }^{5}$ Other empirical work has revealed mixed results. Notably, Brooks (2002) finds evidence that the oil industry has, overall, become more vertically integrated in response to increased liability.

${ }^{6}$ In Warren and Westbrook's (2005) sample of business bankruptcies, $8.8 \%$ of firms have outstanding lawsuits and an additional $7.5 \%$ face judgment liens; $61.2 \%$ of the debt in their sample is secured. Ulph and Valentini's (2004) empirical study finds that increases in environmental liability lead to higher levels of bank debt.

${ }^{7}$ These bonds are named after the rock musician who issued securities backed by the future revenues from previously released albums (Clark, 1997). Corporations securitize assets as diverse as equipment leases, franchise fees, and cash flows from oil reserves (Harrell, Rice, and Shearer, 1997). These are separate legal entities.

${ }^{8}$ This intuition is similar to Pitchford's (1995) observation that lender liability increases the interest rate and consequently reduces the borrower's precautions. This is discussed below in more detail. 
Unfortunately, the level of outside financing by entrepreneurs is not fixed. We show that the entrepreneur will secure an excessive amount of senior debt in order to further dilute the value of the tort claim. In the extreme, the entrepreneur could essentially reduce his liability to zero by issuing securities whose face value exceeds the upper bound on the future firm value. Although secured senior debt is desirable for fixed levels of outside financing, overleveraging leads social welfare to fall because the firm takes too little care to avoid accidents.

We then explore how several different public policies affect the firm's financial structure and the entrepreneur's incentives for care. First, suppose the victims were given priority over the secured senior debtholders in bankruptcy. Although the mandatory subordination of the debtholders discourages overborrowing by the firm, the entrepreneur still takes too little care to avoid harm. (Subordinated financial claimants would require a higher interest rate to compensate them for the risk of nonrepayment, and so the entrepreneur's incentives to take precautions are therefore diluted.) Second, suppose the senior debtholders were held liable for the residual harms unpaid by the injurer. Lender liability also prevents overborrowing but exacerbates the moral hazard problem even further. A rule that we call the Limited Seniority Rule dominates these other policies. Under this rule, the firm may offer a limited amount of senior debt, after which any further borrowing is treated as junior to the tort claim. Limited seniority essentially gives the "best of both worlds." The junior treatment of the debt beyond the preset limit eliminates the incentives for overborrowing, whereas the senior status of the debt up to the preset limit implies that the firm can borrow at a low interest rate, giving better incentives for precaution taking.

The current article is related to several strands of existing research. First, it is closely related to literature on (exogenous) judgment proofness. Shavell (1986) was the first to rigorously analyze the judgment-proof problem - that injurers with limited assets will engage in risky activities too often and will take too little care while doing so. ${ }^{9}$ A number of remedies have been explored, including mandatory liability insurance (Shavell, 1986, 2005), vicarious liability (Dari Mattiacci and Parisi, 2003), and damage multipliers (Boyd and Ingberman, 1994, 1999).

In the corporate finance context, Bebchuk and Fried $(1996,1997)$ have argued that raising the priority of tort victims in bankruptcy and subordinating debt claims will give the debtholders a strong incentive to monitor the borrower ex post, improving the firm's precautions. ${ }^{10}$ Bebchuk and Fried did not anticipate the negative effect of subordination on incentives identified here, however. In work that is the most closely related to ours, Pitchford (1995) considers the impact of imposing liability on lenders. Lenders, anticipating future liability, would require a higher interest rate in compensation. This leaves less remaining wealth for the borrower to lose in the event of an accident, diluting his incentives for care. He suggested the policy of holding the lender partially liable as achieving the optimal outcome. ${ }^{11}$ A similar prescription is made by Boyer and Laffont (1997), who observe the agency problem between the lender and the firm makes it optimal to hold the lender less than fully liable for the harm. The connection between their remedies and ours will be discussed in more detail later.

Our article differs from previous research on the judgment-proof problem. We allow the firm to endogenously judgment proof itself through a broad class of "standard" financial contracts that encompasses senior debt, junior debt, equity, and convertible debt (in addition to a continuum of hybrid securities). This plays a central role in our analysis. First, it allows us to explicitly study the impact of tort liability on the firm's method and level of external financing. Second, it allows us to compare and contrast a comprehensive set of public policy remedies. We provide a clear picture of how various bankruptcy reforms influence the firm's choice of financial structure and

\footnotetext{
${ }^{9}$ See also Summers (1983). Beard (1990) shows that firms may take too much care when investments are pecuniary. Intuitively, expenditures made out of cash reserves are not claimable by tort victims, so tort victims effectively subsidize the firm's pecuniary investments. See also Dari Mattiacci and De Geest (2005).

${ }^{10}$ See Notes (2003). Similarly, Hansmann and Kraakman (1991) argue in favor of shareholder liability.

${ }^{11}$ Lewis and Sappington (2001) generalize Pitchford's binary technology and give the lender more instruments with which to control the firm, including nonmonotonic contracts. Some of Pitchford's main results do not survive this extension. See also Balkenborg (2001).
} 
subsequent precaution levels, and the relative advantages of these bankruptcy reforms over lender liability (either partial or full).

Our article also contributes to the finance literature on the role of agency costs in the design of financial securities (Jensen and Meckling, 1976). ${ }^{12}$ Innes (1990), assuming a fixed capital requirement, shows that debts dominate all other standard financial contracts in terms of the incentives they provide to the borrower to maximize the value of the venture. ${ }^{13}$ Innes's model, like many of the existing models, does not distinguish different types of debt contracts, and thus does not explain why senior debt would be chosen over junior debt. ${ }^{14}$ In our article, the firm's preference for senior debt is driven by the presence of the tort victims. ${ }^{15}$

The article is arranged as follows. Section 2 illustrates some of the key contributions of our article in a simple example. Section 3 lays out the basic assumptions of the model and establishes a social welfare benchmark. Section 4 characterizes the financial decisions and effort choice of the firm. Section 5 considers public policy responses, including the elevation of tort victims in bankruptcy and lender liability. Sections 6 and 7 discuss other remedies of judgment proofness and discuss several extensions. Section 8 concludes.

\section{Example}

- Consider an entrepreneur who needs to raise at least $\$ 300$ to purchase capital —a "taxi medallion." The capital market is competitive and the risk-free interest rate is normalized to zero. The taxi medallion, which does not depreciate in value, will generate an additional cash flow of $\$ 200$ under the control of the entrepreneur. Although the cash flow is riskless, the business activity is risky in the sense that it may cause harm to other people. For the moment, let us assume that there is an exogenous one-in-ten probability that the activity will cause $\$ 1000$ in damages to a tort victim. Notice that this business activity is inherently judgment proof: in the event of an accident, the total assets (the $\$ 300$ medallion plus the $\$ 200$ cash flow) are insufficient to compensate the tort victim for his loss.

For any fixed level of borrowing below the total value of the assets - say $\$ 300$ - it is clear that the entrepreneur would choose to finance the business with secured debt. With senior status, the lender is guaranteed repayment of his loan in the event of an accident and is therefore willing to issue the loan at the risk-free rate of $0 \%$. In the event of an accident, the lender receives the $\$ 300$ taxi medallion and the tort victims claim the $\$ 200$ cash flow. Note that the entrepreneur's equity has an expected value of $\$ 180$ - the entrepreneur keeps the residual $\$ 200$ cash flow $90 \%$ of the time and keeps nothing in the event of an accident. If the debt were junior to the tort claim, on the other hand, then the lender would not be repaid following an accident. A face value of (approximately) \$333 would allow the lender to break even in expectation, corresponding to an interest rate of $11 \%{ }^{16}$ What happens if the entrepreneur borrows $\$ 300$ with junior debt? In such a case, if no accident occurs, the entrepreneur's payoff is $\$ 300+\$ 200-$ $\$ 333=\$ 167$; if an accident occurs, the entrepreneur receives $\$ 0$, assuming that the debt has a junior status relative to the tort claim. ${ }^{17}$ His expected payoff is therefore $90 \%$ of $\$ 167$, or $\$ 150$.

\footnotetext{
${ }^{12}$ Modigliani and Miller's (1958) famous result about the irrelevance of capital structure fails to hold in the presence of taxes, bankruptcy costs, and (as here) agency costs and strategic effects.

${ }^{13}$ Innes assumes, as we do, that the lender's payoff must be nondecreasing in firm profit. This is sensible when lenders can sabotage the firm's results and borrowers can misrepresent their cash flows.

${ }^{14}$ In Hart and Moore (1995), the hard claims of senior debt discipline managerial "empire building." The coexistence of multiple securities with varying durations and seniority may be due to variations in the timing of investments and receivables and the heterogeneous preferences and monitoring abilities of investors (Tirole, 2005).

${ }^{15}$ Perotti and Spier (1993) argue that debt is an effective bargaining tool for extracting concessions from other creditors, including labor unions. Spier and Sykes (1998) point out that senior debt can be used to steal value from tort victims, but do not consider incentive problems. See also Ulph and Valentini (2004).

${ }^{16}$ Ninety percent of $\$ 333$ is approximately $\$ 300$.

${ }^{17}$ In practice, junior debtholders and tort victims receive equal treatment in bankruptcy proceedings. As discussed later, the effect of elevating the bankruptcy status from this status is qualitatively the same. We adopt this simple notion of junior debt for analytical and expositional ease.
} 
Therefore, the entrepreneur's expected payoff is $\$ 30$ higher when the debt is senior to the tort claim.

Senior debt is an effective mechanism for transferring value from the tort victims to the entrepreneur: the entrepreneur is made better off by $\$ 30$ and the tort victims are made worse off by $\$ 30$. To see this, consider the expected payments to the tort victims. When the debt is senior, the taxi medallion is essentially taken "off the table" and the tort victims' recovery is limited to $\$ 200$. That is, the tort victims collect $\$ 20$ in expectation. When the debt is junior, on the other hand, the tort victims can seize the taxi medallion worth $\$ 300$ in addition to the $\$ 200$ cash flow. So the tort victims' recovery following an accident is $\$ 500$, or $\$ 50$ in expectation.

The method of financing does more than simply reallocate value among the different players, however. It can also affect the entrepreneur's effort choice and hence the expected accident losses. To see this, suppose that there are two levels of precaution: low and high. The low level of effort is costless for the entrepreneur and leads to a $20 \%$ accident probability. The high level of effort requires the entrepreneur to make a nonpecuniary investment of $\$ 18$ and reduces the accident probability to $10 \%$. Notice that the high level of effort is socially optimal here: the entrepreneur's cost of effort, $\$ 18$, is outweighed by the $\$ 100$ reduction in the expected accident losses. It is easy to see that, with senior debt, the entrepreneur will take the high level of precaution. The $10 \%$ reduction in probability multiplied by the entrepreneur's $\$ 200$ out-of-pocket cost in the event of an accident outweighs his $\$ 18$ additional cost of effort. With junior debt, on the other hand, the entrepreneur will not take the high level of precaution. Suppose he did. Recall that an $11 \%$ rate of interest would reduce the entrepreneur's personal stake from $\$ 200$ to $\$ 167$. The additional cost of effort, $\$ 18$, is higher than the benefit of this effort, $(0.1)(\$ 167)=\$ 16.7 .^{18}$ This simple example illustrates that the entrepreneur's preferred method of financing — senior secured debt - is aligned with that of society more broadly. If the entrepreneur controlled the level of financing as well, he would issue securities that are backed by the $\$ 200$ cash flow in addition to the $\$ 300$ taxi medallion and can subsequently consume (or hide) the immediate cash infusion of $\$ 200$. Because the lender expects to be repaid in full, the required rate of interest is $0 \%$. Now the company is totally judgment proof: there are no assets for the victims to claim in the event of an accident. The entrepreneur takes the low level of effort here and, in a richer framework, his precautions would be even lower than that.

What can society do to control this behavior? First, suppose that a law were passed that elevated the status of the tort victims in bankruptcy above that of the debtholders. This effectively forces debt into a junior position. On the positive side, this law would prevent the overleveraging identified above. The entrepreneur will limit his borrowing to the $\$ 300$ taxi medallion only. On the negative side, however, the higher interest rate demanded by the lender implies that the entrepreneur will take only the low level of effort. Suppose instead that the lender is held liable for $100 \%$ of the accident victim's losses. Assuming a high level of effort, the interest rate would necessarily rise to $30 \%$ - the first $\$ 300$ of the $\$ 389$ face value reflects the principal of the loan while the remaining $\$ 89$ reflects the lender's expected future liability. From the entrepreneur's perspective, the $10 \%$ reduction in probability multiplied by his $\$ 111$ loss following an accident is outweighed by the $\$ 18$ cost of effort. ${ }^{19}$ Indeed, this example suggests that the entrepreneur's incentives would be even worse with lender liability.

Our proposed Limited Seniority Rule, which allows the entrepreneur to issue senior debt up to a limit of $\$ 300$ and forces further borrowing into a junior subordinated position, does better than either of these other remedies. The entrepreneur would borrow exactly $\$ 300$ and no more, and would subsequently take the high level of precaution. The junior treatment of the additional cash flow eliminates the incentives for overborrowing because overborrowing cannot help to shield the entrepreneur from liability. At the same time, the scheme allows for the senior status

\footnotetext{
${ }^{18}$ If the high effort cannot be supported, then the junior debtholders would demand an interest rate above $11 \%$, further diluting the entrepreneur's incentives.

${ }^{19}$ If there is no accident, the lender receives the $\$ 389$ face value and the firm keeps $\$ 500-\$ 389=\$ 111$. 
of debt up to the level required for productive use. This means that the firm can borrow on the terms that will leave it with the best incentives to take precautions.

\section{Model}

- Consider a privately owner-managed firm. The firm has a project that requires an initial investment of $k$ and will generate a fixed future cash flow of $v>k$. The project also potentially causes harm to society. The magnitude of the harm, $x$, depends on the effort (or precaution) chosen by the firm, $e \in \mathbb{R}_{+}$. Specifically, $x$ is distributed over the interval $\mathcal{X}:=[0, \bar{x}]$, according to a cdf $F(\cdot \mid e)$ which has positive density $F(\cdot \mid e)$ in its support. We assume that higher effort reduces social harm in the sense of $f$ satisfying the monotone likelihood ratio property in $(-x$, e):

$$
(M L R P) \quad \frac{f\left(x^{\prime} \mid e^{\prime}\right)}{f\left(x \mid e^{\prime}\right)}<\frac{f\left(x^{\prime} \mid e\right)}{f(x \mid e)} \text { for any } x^{\prime}>x, e^{\prime}>e, x^{\prime}, x \in \mathcal{X} .
$$

Assuming differentiability of $F(\cdot \mid e)$ with respect to $e,(M L R P)$ implies that $F_{e}(\cdot \mid e)>0$. We assume further that $F_{e e} \leq 0$. When taking an effort of $e$, the firm incurs a nonpecuniary cost of $c(e)$, where $c(0)=0, c^{\prime}(e) \geq 0, c^{\prime \prime}(e)>0, c^{\prime}(0)=0$, and $c^{\prime}(\infty)=\infty$. Effort is unobservable to all parties other than the firm and cannot be directly contracted upon.

The owner-manager is liquidity constrained and finances the project with money raised on the external capital market. ${ }^{20}$ The capital market is perfectly competitive and the risk-free interest rate is normalized to zero. In return for their capital investment, the outside investors receive claims on the future cash flow of the firm, $v$, which is fully contractible. (The specifics of these financial contracts are described in detail below.) The level of funds actually raised by the owner-manager, $K$, may in fact exceed the amount necessary for the project, $k$. We assume that any excess borrowing, $K-k$, can be spent quickly and efficiently by the owner-manager in a way not reachable later by the tort victims or by the outside investors. ${ }^{21}$ For instance, $K-k$ could be immediately consumed by the owner-manager in the form of salary or perks, or paid out to inside shareholders in the form of dividends or special distributions. ${ }^{22}$

Once the cash flow $v$ is generated and the social harm $x$ is realized, the victims sue for damages and the firm is subsequently liquidated. We assume that the tort victims receive compensatory damages equal to their realized harm, $x$, whenever the firm has sufficient cash flows left after repaying any senior financial claims. Under the assumed bankruptcy rules, senior financial claims are paid first, followed by the tort claims, followed by any junior financial claims. ${ }^{23}$ Any remaining cash flow that remains is subsequently enjoyed by the owner-manager.

In the analysis that follows, it is sometimes useful to distinguish two different cases. Suppose first $\bar{x} \leq v-k$. In this case, we will say that the project is not inherently judgment proof in the sense that its cash flow could reimburse both an outside investor for the minimum necessary capital, $k$, and fully compensate the victims for their harms (even if the harms are at the highest level). When $\bar{x}>v-k$, we will say that the project is inherently judgment proof because the firm would face insolvency if the harm were sufficiently large.

\footnotetext{
${ }^{20}$ The firm may have internal funds of $w$ at its disposal for the investment, in which case the project requires total investments of $k+w$, so that it requires outside investment of $k$. In this sense, $k$ is interpreted to be the minimal investment to be raised outside.

${ }^{21}$ For simplicity, there is no direct efficiency loss associated with the excess borrowing. In practice, this may not be the case. The working paper version of this article generalizes the model in this direction. The main results are qualitatively unchanged.

${ }^{22}$ The owner-manager might lease a corporate jet or a luxurious office, or purchase a yacht. As long as the investor believes that the project will generate sufficient cash flows, $v$, and that he is adequately protected by the terms of his financial contract, the investor would be willing to lend in excess of $k$.

${ }^{23}$ In practice, junior debt and tort claims typically share, pro rata, in the value that remains after paying the secured senior claims. Our framework could be adapted to consider this intermediate case without changing the main conclusions.
} 
TABLE 1 Payoffs under Contract $r$

\begin{tabular}{lc}
\hline & Payoffs \\
\hline Investors & $r_{S}+\rho_{J}\left(v-r_{S}-x\right)$ \\
Tort victims & $\min \left\{v-r_{S}, x\right\}$ \\
The firm & $\max \left\{v-r_{S}-\rho_{J}\left(v-r_{S}-x\right)-x, 0\right\}$ \\
\hline
\end{tabular}

Financial contracts. The firm raises capital, $K$, by issuing financial claims that may vary in their status at the time of bankruptcy. A financial contract is formally represented as the firm's repayment requirement specified as a function of the cash flow left after the claims with higher status have been paid. Hence, we consider claims that are either "senior" or "junior" relative to the claims of the tort victims.

The "senior claims" in our model are debt contracts characterized by a single repayment amount, $r_{S} \leq v .^{24}$ These claims are repaid out of the cash flow before the victims are compensated. In practice, senior debt may be secured by the physical capital of the firm or its future cash flow, as with the case of asset securitization strategies (i.e., Bowie bonds). Note that the terms of repayment for these senior claims do not depend on the social harm, $x$. Although our focus is on financial contracting, our framework captures the essence of many different types of judgment-proofing strategies. For example, we can interpret the senior debt in our model as actually being equity that is owned by a "parent," while the firm (a "subsidiary") rents the assets from the parent and controls the risky activity. As described in the Introduction, these asset securitization strategies also have the feature that the assets owned by the parent are not part of a bankruptcy proceeding when the subsidiary becomes insolvent.

"Junior claims" are paid out only after the senior claims and victims have been compensated. Their repayment amount may be a function of any remaining cash flow, $z=v-r_{S}-x$. Formally, an arbitrary junior claim specifies the payout to the investor, $\rho_{J}\left(v-r_{S}-x\right)$, given a cash flow $v$, a senior claim $r_{S}$, and a tort claim of $x$, where $\rho_{J}\left(v-r_{S}-x\right) \in\left[0, \max \left\{v-r_{S}-x, 0\right\}\right]$. As is standard in security design literature, we restrict the set of junior claims by requiring both the payment to the claimant, $\rho_{J}(z)$, and the payment to the firm, $z-\rho_{J}(z)$, to be nondecreasing in the remaining cash flow $z$, for $z \geq 0$. We call the set, $\mathcal{R}$, of junior claims satisfying these properties standard junior claims. All well-known junior claims belong to this set. For instance, a typical junior debt contract with repayment rate $r_{J}$ is described by $\rho_{J}(z)=: \min \left\{r_{J}, \max \{z\right.$, $0\}\}$. An outside equity claim is described by $\rho_{J}(z)=\mu \max \{z, 0\}$, for some $\mu \in(0,1]$, so again $\rho_{J}(z) \in \mathcal{R}$. It is easy to see that convertible debt, levered equity, call options, as well as any mixture of these instruments generate another standard junior claim, $\rho_{J} \in \mathcal{R} .{ }^{25}$

The firm's repayment terms can therefore be represented by a pair, $\mathbf{r}:=\left(r_{S}, \rho_{J}\right)$, such that $r_{s} \leq v$ and $\rho_{J} \in \mathcal{R}$. In the special case where the junior claim is a simple debt contract, we will simply replace the second component by the repayment rate $r_{J}$ (with slight abuse of notation). In general, financial contract $\mathbf{r}$ yields the ex post payoffs to the three parties as shown in Table 1.

The time line is as follows. At date $T=0$, the firm chooses its financial contract $(K, \mathbf{r})$. At date $T=1$, the firm chooses effort $e$. At date $T=1.5$, the harm $x$ is realized. At date $T=2$, the investor is repaid and the tort victim is compensated.

\footnotetext{
${ }^{24}$ That the repayment term takes a single real number is an artifact of the deterministic cash flow. If the cash flow were stochastic, the repayment would be a function, $\rho_{S}(\tilde{v}) \in[0, \tilde{v}]$, depending on the cash flow $\tilde{v}$. With the Innes monotonicity assumption, $\rho_{s}{ }^{\prime}(\cdot) \in[0,1]$, our results will remain valid. See Section 7.

${ }^{25}$ See Innes (1990) and DeMarzo, Kremer, and Skrzypacz (2005) for detailed justification of the monotonicity assumption.
} 
Welfare benchmark. Before proceeding, we establish a useful social welfare benchmark. Assuming that the project is pursued, social welfare is simply

$$
W(e):=v-k-\int_{\mathcal{X}} x f(x \mid e) d x-c(e) .
$$

Neither the financial contracts nor the level of borrowing, $K$, influence social welfare directly. Capital structure will matter later, however, through its indirect effect on firm behavior. Integrating the social welfare function by parts gives

$$
W(e):=v-k-\int_{\mathcal{X}}[1-F(x \mid e)] d x-c(e) .
$$

Suppose that the social planner can decide how much precaution the firm should exert directly. Differentiating $W(e)$ shows that the first-best precaution level, $e_{F B}$, satisfies

$$
\int_{\mathcal{X}} F_{e}(x \mid e) d x-c^{\prime}(e)=0 .
$$

Throughout, we assume that $W(0) \geq 0$, so the project is socially valuable even with zero effort. This assumption will simplify our analysis and ensure that the project will be carried out in the relevant cases studied below. We later discuss the implication of judgment proofing on the project funding decision.

\section{The firm's problem}

- We now study the firm's behavior. Although our focus in this section is to analyze its behavior without any regulation, it is convenient for a later analysis to begin with a slightly general framework in which the lender may be subject to some liability. Specifically, suppose the firm picks $(K, \mathbf{r}, e) \in[k, v] \times[0, v] \times \mathcal{R} \times \mathbb{R}_{+}=: \mathcal{F}$ to initiate the project. We assume that, after the lender is repaid according to $\mathbf{r}$, he is liable to pay $\ell(x)$ when the harm $x$ is realized, where $\ell(\cdot)$ is assumed to be nondecreasing. Then, the lender's ex post payoff is

$$
\pi(x, \mathbf{r}, \ell):=r_{S}+\rho_{J}\left(v-r_{S}-x\right)-\ell(x),
$$

when harm $x$ is realized. If the lender expects the firm to choose $e$, then his ex ante payoff becomes

$$
\Pi(\mathbf{r}, e ; \ell):=\int_{\mathcal{X}} \pi(x ; \mathbf{r}, \ell) f(x \mid e) d x .
$$

Meanwhile, the firm receives an ex post payoff of

$$
u(x ; \mathbf{r}):=\max \left\{v-r_{S}-\rho_{J}\left(v-r_{S}-x\right)-x, 0\right\},
$$

so its ex ante payoff given effort $e$ is

$$
U(K, \mathbf{r}, e):=K-k+\int_{\mathcal{X}} u(x ; \mathbf{r}) f(x \mid e) d x-c(e) .
$$

The firm then faces the problem

$$
\max _{(K, \mathbf{r}, e) \in \mathcal{F}} U(K, \mathbf{r}, e)
$$

subject to

$$
\Pi(\mathbf{r}, e ; \ell) \geq K
$$

and

$$
e \in \arg \max _{e^{\prime} \in \mathbb{R}_{+}} U\left(K, \mathbf{r}, e^{\prime}\right) .
$$


Condition $(I R)$ ensures that the lender breaks even from the financial contract $(K, \mathbf{r})$, when the firm is expected to choose effort $e$. Condition $(I C)$ means that the firm must have the incentive to choose $e$, facing the financial contract $(K, \mathbf{r})$. This is a constraint because the firm cannot commit to a level of precaution ex ante, even though it may wish to do so. ${ }^{26}$ We say that $(K, \mathbf{r}, e) \in \mathcal{F}$ is feasible if it satisfies both $(I R)$ and $(I C)$ and optimal for the firm if it solves the program $[\mathcal{P}(\ell)]$.

The unregulated behavior of the firm. We now analyze the unregulated behavior of the firm. Formally, we consider $[\mathcal{P}(0)]$ : that is, no restriction is placed on the firm's financial decision making (i.e., the amount of borrowing and its choice of financing instruments), and the lender bears no liability (i.e., $\ell(\cdot)=0$ ). Therefore, the firm is free to choose the amount of borrowing, $K$, the financing instruments, $\mathbf{r}$, and its precaution level, $e$. Before proceeding, we characterize the optimal financial structure for the firm and its incentive to take precautions, given that financial structure.

Lemma 1 (Optimality of senior debt). For any feasible $(K, \mathbf{r}, e)$ with a non-debt structure $\mathbf{r}$, there exists a feasible $(K, \hat{\mathbf{r}}, \hat{e})$, with an all-debt structure $\hat{\mathbf{r}}$, which the firm prefers over $(K, \mathbf{r}, e)$. For any feasible $(K, \mathbf{r}, e)$ with an all-debt structure with $r_{J}>0$, there exists a feasible $(K, \hat{\mathbf{r}}, \hat{e})$, with a senior-debt-only structure with $\hat{r}_{J}=0$, which the firm prefers over $(K, \mathbf{r}, e)$. In each case, a shift to any such preferred feasible structure leads to a (weakly) higher level of precaution.

Proof. See the Appendix.

Lemma 1 tells us that, holding the level of capital fixed at $K$, it is both privately and socially optimal for the firm to choose a senior-debt-only structure. ${ }^{27}$ As mentioned above, the private optimality of senior debt stems from its effectiveness as a judgment-proofing device. To illustrate the role of seniority, suppose first that the firm borrows $K$ with (only) junior debt with the payment rate of $r_{J}$. Assume $v-r_{J}<\bar{x}$ so that insolvency arises with positive probability, in which case the (junior) creditor does not always receive her payment $r_{J}$. This scenario is depicted in Figure 1 , which plots the payouts to different parties as functions of $x$.

For a given level of harm, $x$, the tort victim is paid $\min \{x, v\}$, the junior creditor is paid $\min \left\{r_{J}, \max \{v-x, 0\}\right\}$, and the firm receives $\max \left\{v-x-r_{J}, 0\right\}$ (gross of effort cost). The areas, weighted by the densities, represent the expected payments to different parties. Notice that the repayment rate, $r_{J}$, must be inflated to reflect the risk of nonrepayment: $r_{J}>K$.

Suppose instead that the firm borrows $K$ with senior debt, assuming for a moment the same payment rate $r_{S}=r_{J}>K$. The firm would still receive $\max \left\{v-x-r_{J}, 0\right\}$, but the rent is redistributed from the tort victim to the lender: the lender now receives $r_{J}>K$ with certainty and the tort victim receives the remainder, $\min \left\{x, v-r_{J}\right\}$. This redistributed rent can be easily shifted to the firm. Because the lender would receive a strictly higher payoff with senior rather than junior debt (holding the repayment rate fixed), she can be persuaded to charge a lower rate. In fact, the competitive capital market would drive the repayment rate down to a level that allows the lender to break even: $r_{S}=K$. This is shown in Figure 2 .

The firm extracts all of the redistributed rents, that is, the entire gain from diluting the tort claims. Nevertheless, Lemma 1 suggests that this judgment-proofing strategy is socially desirable because the firm chooses a higher level of precaution with senior debt than with junior debt (or other junior claims). A senior claimant is assured repayment of the loan, unlike junior claimants, so the former charges a lower repayment rate than the latter. Hence, the firm is less likely to be insolvent with senior debt. Comparing Figure 1 to Figure 2 shows that, with senior debt, the firm

\footnotetext{
${ }^{26}(I C)$ may bind because, starting at the solution of the relaxed program ignoring $(I C)$, it may pay the firm to change $e$ in a way violating $(I R)$.

${ }^{27}$ There are additional costs associated with high leverage that are beyond the scope of this article. The borrower may succumb to moral hazard and ignore the maintenance of the firm's assets, for example, whereas the lender may lack the expertise to monitor the borrower effectively. See Tirole (2005).
} 
FIGURE 1

DISTRIBUTION OF PAYOFFS UNDER JUNIOR DEBT

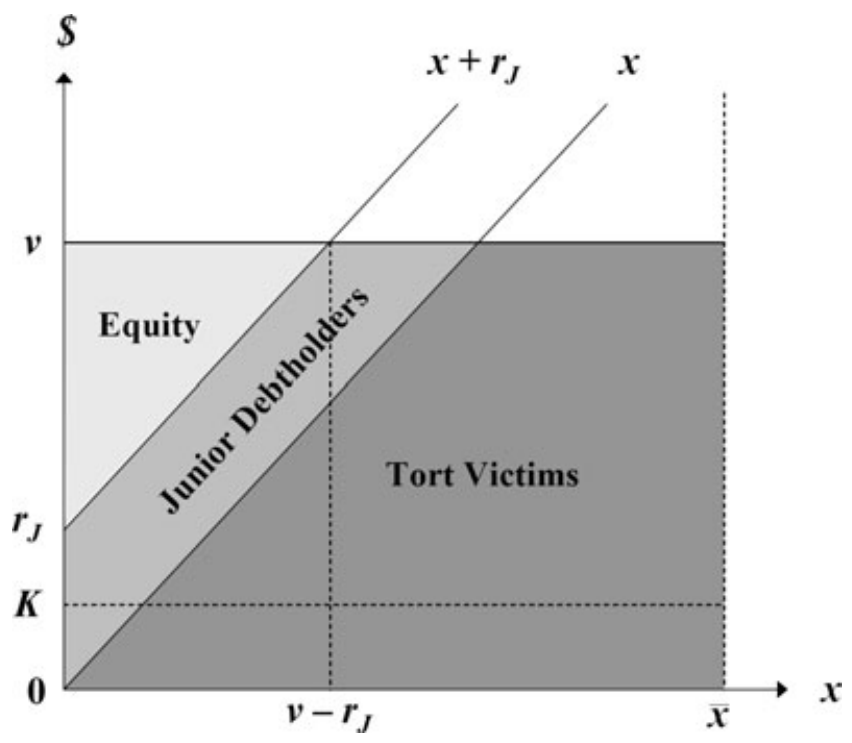

FIGURE 2

DISTRIBUTION OF PAYOFFS UNDER SENIOR DEBT

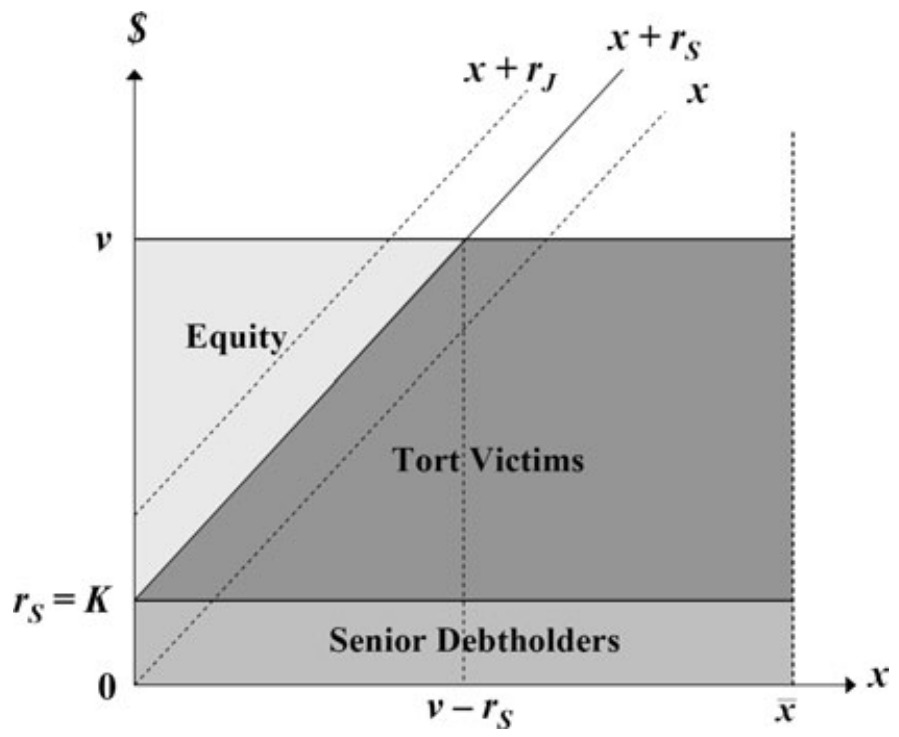

is a residual claimant in more states of nature and thus has a greater incentive to reduce the harm to the tort victims.

Given Lemma 1, we can restrict attention to the senior-debt-only financial structure for the firm. If the firm issues senior debt with any $K \in[k, v]$, the break-even repayment rate is simply $r_{S}=K$ because the debtholder has seniority over tort victims. From (3) above, the firm's ex post payoff is

$$
u_{0}(x ; K):=u(x ; K, 0)=\max \{v-K-x, 0\} .
$$


Hence, its ex ante payoff given effort $e$ is

$U_{0}(K, e):=K-k+\int_{0}^{v-K}(v-K-x) f(x \mid e) d x-c(e)=K-k+\int_{0}^{v-K} F(x \mid e) d x-c(e)$,

where the equality follows from integration by parts.

The unregulated behavior of the firm, $\left(K_{0}, e_{0}\right)$, must then maximize $U_{0}(K, e)$. The behavior is characterized as follows. Given any effort $e$, the firm's marginal benefit from raising its borrowing is

$$
\frac{\partial U_{0}(K, e)}{\partial K}=1-F(v-K \mid e) .
$$

This expression reveals the judgment-proofing benefit of overborrowing. Whenever the firm is insolvent (i.e., $x>v-k$ ), the additional repayment to the lender comes out of the fund that would have been used for the tort award, given the seniority of the debt. Hence, essentially, each additional dollar borrowed is paid out of the tort victims' pockets with probability $1-F(v-$ $K \mid e$ ). Consequently, the marginal benefit of increasing the senior debt is strictly positive for any $K<v$, which implies that the firm will borrow $K_{0}=v$.

The implication for firm precaution is quite clear. Given any $K \in[k, v]$, the firm's precaution level $e_{0}(K)$ is determined by

$$
\frac{\partial U_{0}(K, e)}{\partial e}=\int_{0}^{v-K} F_{e}(x \mid e) d x-c^{\prime}(e)=0 .
$$

Because $\partial^{2} U_{0}(K, e) / \partial e \partial K=-F_{e}(v-K \mid e)<0$ for any $K<v, e_{0}(\cdot)$ is strictly decreasing in range. In words, an increased senior debt lowers the firm's exposure to tort liability, reducing its incentive for precaution. In fact, as is clear from (6), given $K=v$, the firm has no incentive for any precaution, that is, $e_{0}(v)=0$.

Proposition 1. Without any policy intervention, the firm borrows $K_{0}=v$ with senior debt and takes no precautions, $e_{0}=0$.

Note that even when the firm is not inherently judgment proof $(\bar{x} \leq v-k)$, it creates "artificial" judgment proofness by borrowing up to its cash flow.

\section{Public policy responses}

- This section considers several remedies to the judgment-proof problem, including extending liability beyond the injurer to the lenders and senioritizing the bankruptcy status of tort claims. These two remedies share a common purpose of expanding the recovery of damages for the victims from a judgment-proof injurer. They may differ, however, in their incentives for precaution taking and borrowing. In order to meaningfully compare these remedies, we first establish a more realistic welfare benchmark than the one established before.

Welfare target with moral hazard. Suppose the social planner controls all aspects of the firm's behavior, except for its precaution decision. Specifically, the planner chooses the amount of borrowing $K \geq k$, and the terms of the financial contract, $\mathbf{r}$, for the firm. She also imposes a liability of $\ell(\cdot)$ on the lender, where $\ell(\cdot)$ is nonnegative and nondecreasing. We denote the set of feasible liability rules by $\mathcal{L}$. These choices are subject only to the constraints that the lender must break even (i.e., $(I R)$ ) and the firm must have incentive to choose the precaution the planner wishes to implement (i.e., $(I C)$ ). Formally, the social planner would solve

$$
\max _{(K, \mathbf{r}, e, \ell)} W(K, e)
$$

subject to

$$
(K, \mathbf{r}, e) \in \mathcal{F} \text { satisfies }(I R) \text { and }(I C) \text {, and } \ell \in \mathcal{L} \text {. }
$$


Although the regulators probably do not have either the information or the power to control the amount of borrowing or the terms of financial contracts of firms, the program $[S W]$ yields a more realistic welfare target than the first-best level. The next proposition characterizes the optimal borrowing and precaution behavior, $\left(K^{*}, e^{*}\right)$, that the planner would wish to implement.

Proposition 2 (Constrained efficiency). The solution of the problem $[S W]$ involves $K^{*}=k$ and $e^{*}=e_{0}(k)$. No liability is imposed on the lenders, $\ell(x)=0$, and the financial contract involves only senior debt, $\mathbf{r}=(k, 0)$.

This result suggests that the underprovision of effort chosen by the unregulated firm is attributed entirely to its excess borrowing. Had the firm borrowed $K=k$, then the firm would have chosen the (constrained) efficient level of precaution $e_{0}(k)$. The reason is the following. The unregulated firm dilutes the tort claims by choosing senior debt and by borrowing beyond the necessary level. For a fixed level of borrowing, senior debt improves incentives (Lemma 1). Excessive borrowing, however, worsens the incentives.

We will now show that subordination and lender liability serve to curb excessive borrowing but introduce their own problems.

Mandatory subordination. Under mandatory subordination, all financial claims are restricted to be junior to the tort claims in their bankruptcy priority. Given the junior status of the debt, the tort victims have priority, meaning that they will receive up to the level allowed by the cash flow, or $\min \{v, x\}$. This means that raising the level of borrowing cannot help the firm to avoid tort liability. Mandatory subordination controls the overleveraging problem, with the firm choosing $K_{\text {sub }}=k$.

Given Step 2 of Lemma 1' (see the Appendix), the firm prefers junior debt among all standard junior claims. The equilibrium repayment rate, $r_{s u b}$, and the firm's equilibrium effort choice, $e_{s u b}$, are determined jointly. Given the effort $e_{s u b}$, the repayment rate $r_{s u b}$ must be chosen to satisfy the lender's break-even condition $(I R)$,

$$
\int_{0}^{v} \min \left\{r_{\text {sub }}, v-x\right\} f\left(x \mid e_{\text {sub }}\right) d x=k .
$$

Given the repayment rate, $r_{\text {sub }}$, the effort choice $e_{\text {sub }}$ must satisfy the firm $(I C)$, or the associated first-order condition,

$$
\int_{0}^{v-r_{s u b}} F_{e}\left(x \mid e_{s u b}\right) d x=c^{\prime}\left(e_{s u b}\right)
$$

The equilibrium outcome depends on whether the project is inherently judgment proof. If it is not inherently judgment proof, the investor can break even with the repayment of $k$, so $r_{\text {sub }}=k$. Then, because $v-k \geq \bar{x}$, (8) coincides with (1), which implies that the firm will choose the first-best effort $e_{F B}$. Hence, mandatory subordination implements the social optimum in this case. If the project is inherently judgment proof, however, the lender must charge $r_{s u b}>k$ to break even. This means that the firm is more likely to be insolvent relative to the senior debt case, thus leading to too little precaution, that is, $e_{s u b}<e_{0}(k)$. Hence, the constrained efficient precaution level, $e^{*}=e_{0}(k)$, is not attainable by subordination. In either case, because $W(0) \geq 0$ and because the firm does not fully compensate the tort victims, the joint payoff for the firm and the lender is nonnegative, so the project will be financed. In particular, $r_{s u b}<v$. It then follows from (8) that $e_{\text {sub }}>0$. Recall that, without subordination, the firm would overborrow to its cash flow limit, $K_{0}=v$, and choose no precaution. Hence, the debt subordination would clearly improve welfare. The results are summarized as follows.

Proposition 3. Suppose the firm is allowed to employ only (standard) junior claims. Then, the firm never borrows more than $k$, but chooses too little precaution $e_{s u b}<e^{*}$ if the project 


\section{FIGURE 3}

\section{DISTRIBUTION OF PAYOFFS UNDER LENDER LIABILITY}

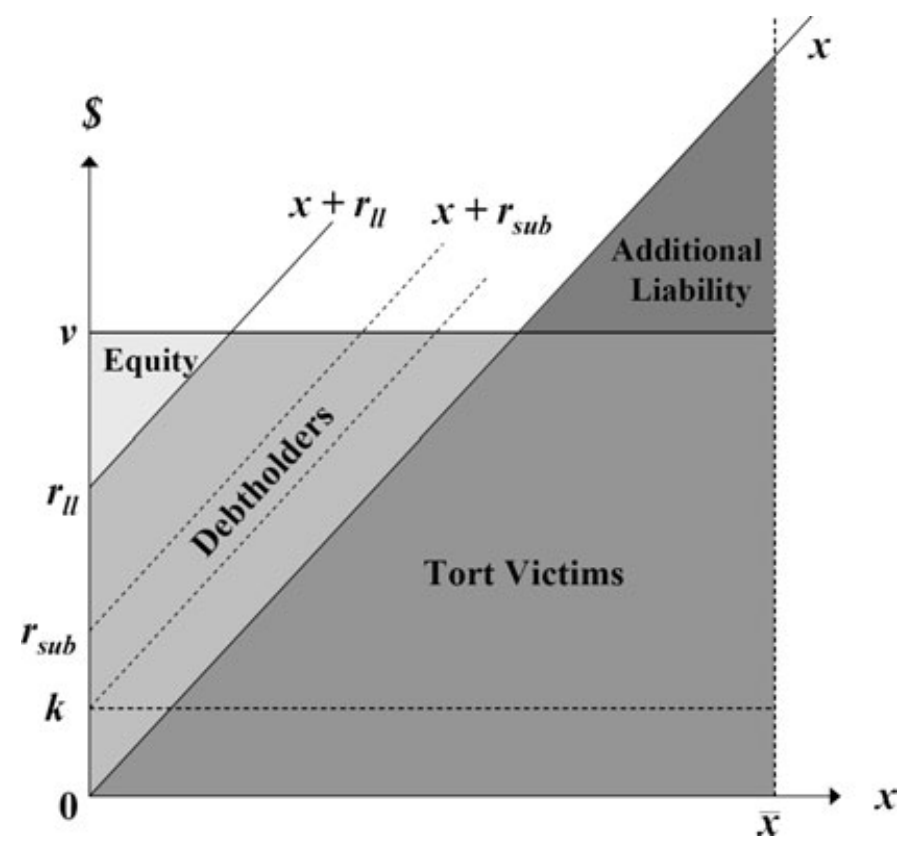

is inherently judgment proof. Subordination improves social welfare (relative to unregulated behavior).

In sum, subordination trades off two sources of precaution incentives. On the one hand, it eliminates overleveraging, which improves the firm's precaution incentives. But at the same time, the switch from senior to junior debt worsens the firm's incentives.

Lender liability. Now suppose that the lender bears the entire residual liability for the damages suffered by the tort victims when the firm is unable to compensate them ex post. Because the additional liability imposed on the lender causes him to raise its repayment rate to a point that will allow him to break even, the liability is in fact shifted to the firm ex ante.

At first glance, lender liability looks similar to debt subordination. As before, the firm thus cannot avoid liability by raising its debt, so the firm would never borrow more than its productive use, that is, $K_{l l}=k$. If the social harm never exceeds the cash flow $(\bar{x} \leq v)$, then lender liability is precisely the same as debt subordination. When the harm level may exceed the cash flow $(\bar{x}>v)$, however, then lender liability and debt subordination generate different incentives for care. In such a case, the lenders have far more to lose with unlimited lender liability: in addition to the risk of nonrepayment of principal and interest, they also run the risk that the tort victims will sue them and recover damages from the lender's personal assets. The additional liability of the lender is depicted in Figure 3 as the triangle above the cash flow $v{ }^{28}$

Anticipating higher future liability, the lenders would require an interest rate that is even higher than the rate with subordination, $r_{l l}>r_{s u b}$. This clearly reduces the firm's equity stake, further diluting the incentives for care.

\footnotetext{
${ }^{28}$ If the harm never exceeds the cash flow (i.e., $\bar{x} \leq v$ ), then the additional liability triangle in Figure 2 disappears, so lender liability coincides with subordination.
} 
To be more precise, let $\left(r_{l l}, e_{l l}\right)$ be the equilibrium repayment rate and precaution choice under lender liability, assuming that the project will be financed. As before, we have

$$
\int_{0}^{\bar{x}} \min \left\{r_{l l}, v-x\right\} f\left(x \mid e_{l l}\right) d x=k,
$$

and

$$
\int_{0}^{v-r_{l l}} F_{e}\left(x \mid e_{l l}\right) d x=c^{\prime}\left(e_{l l}\right)
$$

If $\bar{x} \leq v$, then comparing (7) with (9) confirms that $r_{l l}=r_{s u b}$, so $e_{l l}=e_{s u b}$. If $\bar{x}>v$, however, the extra liability borne by the lender causes him to charge a higher rate, or $r_{l l}>r_{\text {sub }}$, which means that the firm is more likely to be insolvent, and thus will have a lower incentive for precaution, that is, $e_{l l}<e_{s u b}$. In either case, our assumption of $W(0) \geq 0$ ensures that the project will be initially launched and that $r_{l l} \leq v$ and $e_{l l} \geq 0$.

Proposition 4. If $\bar{x} \leq v$, then unlimited lender liability yields the same outcome as subordination. If $\bar{x}>v$, then unlimited lender liability induces lower precautions than subordination. In either case, the firm never borrows more than $k$. Lender liability improves social welfare relative to unregulated behavior.

Whereas lender liability and debt subordination are equally effective at eliminating overleveraging, the incentive problem is more pronounced with lender liability. Intuitively, the lender faces liability risks in addition to the risk of nonrepayment of principal and interest, and the higher interest rate required by the lender exacerbates the incentive problem. It is worth highlighting that the benefit of lender liability arises only due to the firm's strategic judgment proofing, in the form of overleveraging. Lender liability is never beneficial if the firm's borrowing is fixed at $k$. Further, the benefit of deterring overleveraging applies only to senior claims. If all claims were junior (for instance, because the firm has no securable asset), there would be no benefit from lender liability in our model.

Corollary 1. If the firm can only issue (standard) junior claims, then lender liability can only worsen the incentive for precaution taking, strictly so if $\bar{x}>v$.

Proof. If the firm can only use junior claims, then it would use only junior debt (by Step 2 of Lemma $1^{\prime}$ ). Hence, the case without lender liability would coincide with mandatory subordination. The result then follows because mandatory subordination (strictly) dominates lender liability (if $\bar{x}>v)$.

This same logic would apply to placing liability on outside equityholders. An outside equityholder, anticipating future liability for the misconduct of the entrepreneur, would demand a greater proportion of the firm's equity in return. This would leave the entrepreneur with a smaller proportion of the equity, diluting his incentives for care.

We next propose a liability rule that does attain constrained efficiency.

Optimal liability scheme: limited seniority rule. We now introduce a liability rule, called the Limited Seniority Rule, that implements the constrained efficient outcome, $\left(K^{*}, e^{*}\right)$, as defined in Proposition 2. Under this rule, a financial claim's "seniority" is honored only up to a certain limit, $k$. Suppose that a firm borrowed $K>k$ with senior debt. In the bankruptcy court, only the amount $k$ would be treated as "senior" debt, having a priority over tort claims. The remaining portion, $K-k$, would be treated as junior debt. Equivalently, this rule requires that the financial claims on the firm's cash flow be "junior" up to $v-k$, while the remaining portion of cash flow, $k$, may be distributed according to the standard Absolute Priority Rule. 
The effect of this rule can be analyzed as follows. First, note that our earlier result concerning the private optimality of senior debt (i.e., Lemma $1^{\prime}$ ) extends to this rule, so there is no loss in restricting attention to senior debt. Hence, suppose the firm obtains senior debt with $K \geq k$. Given an equilibrium repayment rate $\hat{r}(K)$, the lender will receive

$$
\begin{cases}\min \{\hat{r}(K), v-x\} & \text { if } x \leq v-k \\ k & \text { otherwise. }\end{cases}
$$

Given that the lender anticipates the firm to choose $\hat{e}(K)$, the lender breaks even if

$$
\hat{r}(K) F(v-\hat{r}(K) \mid \hat{e}(K))+\int_{v-\hat{r}(K)}^{v-k}(v-x) f(x \mid \hat{e}(K)) d x+k(1-F(v-k \mid \hat{e}(K)))=K .(11)
$$

Meanwhile, the firm's incentive compatibility requires

$$
\int_{0}^{v-\hat{r}(K)} F_{e}(x \mid \hat{e}(K)) d x-c^{\prime}(\hat{e}(K))=0 .
$$

Observe from (11) that $\hat{r}(k)=k$. That is, if the firm borrows the productive requirement, $k$, it does not bear any additional liability, so the repayment rate of $k$ will break even. Substituting $\hat{r}(k)=k$ into (12) shows that the firm's precaution choice will be constrained efficient, that is, $\hat{e}(k)=e^{*}$.

We now show that the firm would never borrow more than $k$. Suppose that the firm did in fact borrow $K>k$. Then, the firm's ex ante payoff will be (with integration by parts)

$$
\hat{U}(K)=K-k+\int_{0}^{v-\hat{r}(K)} F(x \mid \hat{e}(K)) d x-c(\hat{e}(K)) .
$$

Differentiate this with respect to $K$, using the envelope theorem, to obtain

$$
\hat{U}^{\prime}(K)=1-F(v-\hat{r}(K) \mid \hat{e}(K)) \hat{r}^{\prime}(K) .
$$

Next, differentiate totally (11) to obtain

$$
F(v-\hat{r}(K) \mid \hat{e}(K)) \hat{r}^{\prime}(K)+\left[\int_{v-\hat{r}(K)}^{v-k} F_{e}(x \mid \hat{e}(K)) d x\right] \hat{e}^{\prime}(K)=1 .
$$

Substituting (14) into (13) gives

$$
\hat{U}^{\prime}(K)=\left[\int_{v-\hat{r}(K)}^{v-k} F_{e}(x \mid \hat{e}(K)) d x\right] \hat{e}^{\prime}(K)<0,
$$

where the last inequality holds because $F_{e}>0$ and $e^{\prime}(K) \leq 0$. Because the inequality yields a contradiction, we conclude that the firm never borrows more than $k$. The following conclusion is then immediate.

Proposition 5. The Limited Seniority Rule that treats any borrowing beyond a limit, $k$, as junior to the tort claim implements the constrained efficient outcome $(K, e)=\left(k, e^{*}\right)$.

When compared with mandatory subordination and lender liability, the Limited Seniority Rule involves less compensation to the tort victims ex post. Nevertheless, the rule generates the best incentives for precautions by the firm. Also note that our rule respects absolute priority (up to a limit), and therefore implies less interference with the existing bankruptcy priority rules.

In practice, the exact seniority limit $k$ may not be perfectly observable by the policymaker, so the latter may err either by being too generous or too stingy in her treatment of debt seniority. The Limited Seniority Rule is forgiving of such errors, however, in that its relative desirability is robust to even large errors. To see this, observe that mandatory subordination is a special case of the current rule where the seniority limit is set at zero, forcing all borrowing to be junior to the tort claim. The Limited Seniority Rule with a limit set (inaccurately) in $(0, k)$ will clearly dominate mandatory subordination and thus also lender liability. Likewise, the Limited Seniority Rule will dominate unregulated behavior as long as the limit is set in $\left(k, K_{0}\right)$. Consequently, for 
a very broad range of "inaccurate" limits, the rule will produce a better outcome than mandatory subordination, lender liability, or no regulation at all. In particular, in the absence of an accurate estimate of $k$, a conservative approach that would limit "seniority" to the debt associated with initial setup investment will outperform the mandatory subordination and at the same time will prevent the overleveraging problem.

\section{Other remedies}

- The three remedies to the judgment-proof problem discussed so far-debt subordination, lender liability, and limited seniority - all have focused on debt contracts and the regulation of bankruptcy. We will now discuss additional remedies - partial lender liability, shareholder liability, mandatory liability insurance, and punitive damages.

$\square \quad$ Partial lender liability. Pitchford (1995) and Boyer and Laffont (1997) advocate the idea of holding the lender partially liable for the social harm. Our Limited Seniority Rule can be interpreted in this light, because exposing part of the financial claim to tort victims is a way of holding the lender partially liable. Specifically, the constrained optimum can be implemented by holding the lender liable for $\ell(x ; K, k)=\min \{\max \{x-(v-K), 0\}, K-k\}$ (without any debt subordination). Notice that, given our judgment-proofing issue, the extent of the lender's liability must vary with the extent of borrowing, which differs from the existing proposals.

Alternatively, one could set the lender liability equal to $\min \{x, v-k\}$, as proposed by Pitchford (1995). Indeed, the constrained optimum would be obtained if the debt contract required the firm to reimburse $\min \{x, v-k\}$ to the lender in the event of an accident. ${ }^{29}$ Note that the repayment rate is decreasing in $v-x$. This makes the contract nonstandard, violating our "monotonicity" assumption. Interestingly, if the parties could contract on $x$, then partial lender liability would no longer be optimal. The social planner could achieve an even better outcome by raising the lender liability beyond $v-k$, possibly up to full liability. For instance, with full lender liability, the lender may induce the firm to choose $e_{F B}$ by charging less than $k$ when there is no accident and more than $k+x$ when there is an accident. ${ }^{30}$

Shareholder liability. Our model has very important implications for shareholder liability. ${ }^{31}$ First, policies that allow tort victims to seize the entrepreneur's personal assets-home equity and retirement plans, for example - would lead to improved incentives for care. Facing personal liability, the entrepreneur would better internalize the harms that he causes to society. Whether outside shareholders should be held liable depends on their ability to influence the firm's behavior via monitoring or sophisticated contracting. If they have sufficient control over the firm's behavior, shareholder liability may be desirable. ${ }^{32}$ More realistically, though, outside shareholders tend to be passive, lacking such an ability. In that case, outside equityholders' liability would worsen the entrepreneur's incentives rather than improve them. An outside equityholder, anticipating future liability for tort damages beyond his equity stake, would demand a greater proportion of the company's stock to compensate for that risk. (This greater proportion of stock is analogous to the higher interest rate that would be demanded by debtholders in the case of lender liability.) The entrepreneur is left with a smaller equity stake than otherwise, and hence less of an incentive to take precautions to avoid future liability. In fact, the logic of Lemma 1 implies that the firm's precaution incentive would be even worse under this regime than under lender liability. This insight provides some support for the rule of limited liability in U.S. corporate law.

\footnotetext{
${ }^{29}$ The senior repayment rate depends on the harm $x$, which is assumed away in our model.

${ }^{30}$ This problem does not arise in Pitchford (1995) due to the binary state. See also Lewis and Sappington (2001).

${ }^{31}$ See Hansmann and Kraakman (1991), who argue that the prevailing rule of limited liability for corporation offers few, if any, advantages over a rule of unlimited liability.

${ }^{32}$ As noted earlier, third-party liability leads to the constrained optimum when the third party can charge the firm reimbursement contingent on the level of social harm. In this vein, Pitchford (1993) established equivalence between outside shareholder responsibility, mandatory insurance, and third-party superfund scheme.
} 
Mandatory liability insurance. Mandating that the injurers purchase liability insurance is a simple way of ensuring the tort victims' recovery of their court awards. As Pitchford (1993) and Shavell (2005) observe, if a full-insurance provider can monitor and control the injurer's precaution level (say by conditioning its payout or insurance premium on this level), the provider will require the firm to choose a socially efficient level of precaution. In practice, however, insurance providers are unlikely to possess fully effective monitoring capabilities. For instance, in the context of the taxi accidents, precautions would take the form of a taxi company's screening for careful drivers at the hiring stage and monitoring their driving practices. Such intimate involvement with the management of the business is often beyond the expertise of insurance providers. Without monitoring, liability insurance would lead to higher insurance premiums and would reduce the injurer's precautions. Moreover, if the liability insurance coverage were partial rather than full, so the firm's assets were partially exposed to tort victims, then the firm would still borrow excessively to completely judgment proof itself. With complete insurance coverage, there would be no need for further judgment proofing. Either way, the firm has no incentive to invest in precautions, for it is completely shielded from ex post liability. In other words, the standard moral hazard problem associated with insurance compounds the judgment-proof problem, which aggravates the incentives.

$\square \quad$ Damage inflation: punitive damages. The merits of punitive damages have been widely debated among legal scholars (see Polinsky and Shavell, 1998 for a survey). Because judgment proofness typically leaves victims undercompensated, punitive damages may be one possible way to hold the judgment-proof defendant accountable. Although inflating damages does little to extract payment from a bankrupt injurer, it raises the payment when the injurer is not bankrupt. This is not necessarily a good thing, however (see Boyd and Ingberman, 1994, 1999). First, damage inflation has a dubious effect on incentives in the presence of exogenous judgment proofness. Damage inflation increases damage payments when the harms to society are very low - namely when the injurer is solvent whether or not the damages are inflated. Hence, damage inflation imposes a greater punishment in exactly those states of nature that society would like to encourage. Second, inflating damages creates more temptation for the firm to resort to judgment proofing. Inflated damages mean that the injurer has more to lose in the solvent state, thus motivating her to shield her asset by judgment proofing. In sum, inflating damages does not seem useful in the context of judgment proofness and judgment proofing.

\section{Extensions}

- Richer contracting possibilities and lender monitoring. We have considered a broad set of financing contracts that encompass most of the commonly observed financing arrangements. It is of (at least theoretical) interest to consider even richer contracting possibilities. For example, we can imagine junior claims that do not satisfy the monotonicity properties assumed in $\mathcal{R}$, or senior claims whose payment requirements depend on realized harm $x$, or the investor may be able to monitor the firm's effort. Although contracts outside $\mathcal{R}$ are not common in reality, they are at least theoretically interesting because often such contracts may dominate the ones in $\mathcal{R}$ in performance. $^{33}$

As pointed out by Boyer and Laffont (1997), the improved contracting between the lender and the firm makes it more desirable to regulate the lender. ${ }^{34}$ This is true even in the presence of judgment proofing. Without any regulation, the lender's improved ability to control the firm's behavior via sophisticated monitoring and contracting will simply enable them to promote their

\footnotetext{
${ }^{33}$ Innes (1990) shows that a financial claim which charges high repayment when the cash flow is low and a lower repayment when the cash flow is high does better than a debt. See Lewis and Sappington (2001) for a similar point.

${ }^{34} \mathrm{~A}$ related counterpoint is made by Hiriart and Martimort (2006), who study extended liability in the presence of public regulation of the firm. They find that incompleteness of regulatory contracts makes extending liability more desirable.
} 
joint interest more effectively. They will engage in a variety of judgment-proofing strategies to simultaneously create more firm value and protect that value from the reach of future tort victims. The policy interventions discussed above-subordination, lender liability, and limited seniority - all force the lender and the firm to jointly internalize the social harm they cause. An improved contract between the two parties enables them to implement the level of precaution in their best joint interest, and these policies can better align their joint interest with social welfare. As with Boyer and Laffont (1997), if the lender can monitor the firm's precaution accurately, the agency problem between the two parties disappears. In this case, full lender liability will yield the first-best outcome: the firm will borrow $K=k$ with a contract that punishes the firm whenever it does not pick the first-best effort level.

Victim precautions. Our analysis has assumed that only the firm can take precautions to avoid accidents. In reality, potential victims can also take precautions to avoid accidents and to mitigate their damages in the event that they do occur. In the taxi cab example, pedestrians can be more careful when walking near traffic. Policies that "make the victim whole" following an accident — such as unlimited lender liability — will lead the victim to take too little care. ${ }^{35}$ Debt subordination performs better than unlimited lender liability in this regard. Because the victim bears a residual loss with debt subordination, the victim takes a higher level of care. Because the tort victim bears an even higher loss when debt is senior rather than junior, our Limited Seniority Rule performs best of all. With the Limited Seniority Rule, the junior status of the tort victim encourages greater care levels by the victim, and the lower interest rate encourages greater precautions by the firm.

$\square \quad$ Uncertain cash flows and capital requirements. Thus far, we have assumed that the cash flow, $v$, is deterministic and the productive requirement, $k$, is known. These assumptions, made primarily for simplicity, may not hold in reality. Our results are largely robust to relaxing these assumptions, however. Suppose the cash flow $v$ is a random variable. Innes (1990) shows that debt is preferable to all other standard (i.e., "monotonic") financial claims (which, as noted earlier, include all plausible financial claims) in a model without tort victims, so there would be little loss in restricting attention to senior debt. More importantly, the firm's preference for senior debt over junior claims and its tendency for overleveraging remain unchanged in this case, because the "judgment-proofing" benefits of these practices do not depend on the stochastic nature of the cash flow. Hence, the firm will choose senior secured debt and borrow in excess of its productive use. Some of the remedies to this problem — namely subordination and lender liability - will lead to the same tradeoffs as discussed before. The optimality of the Limited Seniority Rule extend to this new environment, except that the scope of the "junior treatment," $v-k$, would be random instead of deterministic.

Activity levels. We have so far assumed that the firm's activity is socially justified even when it exerts no precaution. Relaxing this assumption identifies an additional role for regulation. Suppose the firm's activity is sufficiently harmful that it is socially unjustifiable, without sufficient precaution. Without any regulation, the various judgment-proofing strategies could enable the firm to engage in harmful activities even without any precaution. The public policies discussed above may regulate the firm's activity decisions. For instance, in the perfect contracting environment, full lender liability will force the firm and the lender to internalize the social harm caused by their activity, resulting in the optimal decision. As Boyer and Laffont (1997) note, if there is moral hazard or adverse selection in the investment, however, full lender liability may prevent even a socially justifiable project from being pursued. Such problems may render partial lender liability or the Limited Seniority Rule optimal.

\footnotetext{
${ }^{35}$ The law and economics literature has suggested various solutions to these so-called bilateral accidents, including contributory negligence. Our framework assumes that the firm's effort level is unobservable and not contractible, preventing the implementation of these negligence rules. 


\section{Conclusion}

- This article has considered the problem faced by an entrepreneur when raising capital to finance a risky business activity. In order to shield his assets from future tort claimants, and to secure capital at lower cost, the entrepreneur has a strong incentive to issue claims that are senior to any future claims by tort victims. Holding the level of borrowing fixed, the entrepreneur's private decision to use senior debt is also socially desirable: senior debt leads to higher levels of precaution and hence a higher social surplus than either junior debt or outside equity. The entrepreneur will tend to borrow too much, however, and this leads to lower precautions. Public policies that prevent strategic judgment proofing may or may not be in society's interest ex ante. Debt subordination and lender liability both eliminate overleveraging. By itself, this is a good thing: lower levels of borrowing implies higher levels of precaution. But holding the level of borrowing as fixed, both policies lead to suboptimal precautions and higher levels of social harm (lender liability performing worst). The Limited Seniority Rule allows senior debt only up to a predetermined limit, and thus limits the scope of the elevation of the torts' bankruptcy status. Although least protective of the interest of tort claimants compared with other policies, this rule achieves the constrained social optimum: it prevents overleveraging and also creates the highest achievable incentives for care.

The main lesson of our article is that firms, when left unregulated, will tend to engage in judgment-proofing strategies. These strategies not only leave the victims undercompensated, they also lead the firms to take too few precautions to avoid causing harm. Although our article focused primarily on financial strategies, namely the firm's choice of capital structure and securitization, it would be interesting to more formally explore other judgment-proofing strategies such as vertical and horizontal disintegration. Whereas our analysis suggests that regulating such practices may be socially desirable, the precise form and degree of regulation requires careful assessment of the incentives facing the firm and is left for future research.

\section{Appendix}

- We prove a more general version of Lemma 1 for any nondecreasing $\ell(\cdot) \geq 0$, Lemma $1^{\prime}$.

Proof of Lemma 1'. The proof of the first statement consists of two steps:

Step 1. Consider any all-debt financial structure, $(K, \mathbf{r})$, with $\mathbf{r}=\left(r_{S}, r_{J}\right)$. Given such a structure, the firm's choice of precaution is unique and nonincreasing in the sum $r_{S}+r_{J}$, and the surplus the firm collects is strictly decreasing in $r_{S}+r_{J}$ for $r_{S}+r_{J} \in(0, v)$.

Proof. Fix any all-debt financial structure, $(K, \mathbf{r})$, with $\mathbf{r}=\left(r_{S}, r_{J}\right)$. Given the structure, if the firm picks $e$, it collects the utility of

$$
U(K, \mathbf{r}, e)=K-k+\int_{0}^{\bar{x}} \max \left\{v-r_{S}-r_{J}-x, 0\right\} f(x \mid e) d x-c(e) .
$$

Integrating by parts, this can be rewritten as

$$
U(K, \mathbf{r}, e)=K-k+\int_{0}^{v-r_{S}-r_{J}} F(x \mid e) d x-c(e) .
$$

Given the assumptions made on $F(x \mid \cdot)$ and $c(\cdot), U(K, \mathbf{r}, \cdot)$ is strictly concave and admits an interior maximizer. Further, the function satisfies a single crossing property with respect to $\left(-r_{S}-r_{J}, e\right)$, hence, the maximizer, $\bar{e}\left(r_{S}+r_{J}\right)$, of $U(K$, $\mathbf{r}, \cdot)$ must be nonincreasing in $r_{S}+r_{J}$. Let $\mathcal{U}\left(r_{S}+r_{J}\right):=\max _{e \in \mathbb{R}_{+}}\left\{K-k+\int_{0}^{v-r_{S}-r_{J}} F(x \mid e) d x-c(e)\right\}$ be the associated maximized value. By the envelope theorem, for $r_{S}+r_{J} \in(\max \{0, v-\bar{x}\}, v)$,

$$
\mathcal{U}^{\prime}\left(r_{S}+r_{J}\right)=-F\left(v-r_{S}-r_{J} \mid \bar{e}\left(r_{S}+r_{J}\right)\right)<0,
$$

which proves the last statement.

Step 2. For any feasible $(K, \mathbf{r}, e)$ with non-debt structure there exists a feasible $(K, \hat{\mathbf{r}}, \hat{e})$ with all-debt structure $\hat{\mathbf{r}}$, which the firm prefers over $(K, \mathbf{r}, e)$. A shift to any feasible all-debt structure that the firm prefers results in a (weakly) higher precaution. 
Proof. Fix any $(K, \mathbf{r}, e)$ with non-debt structure (i.e., $\rho \not \equiv 0, \rho \in \mathcal{R})$, satisfying $(I R)$ and $(I C)$. We consider an all-debt structure $\left(K, \hat{\mathbf{r}}\right.$, with $\left.\hat{\mathbf{r}}:=\left(r_{S}, \hat{r}_{J}\right)\right)$, where $\hat{r}_{J}$ is chosen so that

$$
\begin{gathered}
\Pi(\hat{\mathbf{r}}, e, \ell)=\Pi(\mathbf{r}, e, \ell), \\
\Leftrightarrow \int_{0}^{v-r_{S}-\hat{r}_{J}} \min \left\{\hat{r}_{J}, v-r_{S}-x\right\} d F(x \mid e)=\int_{0}^{\bar{x}} \rho\left(v-r_{S}-x\right) d F(x \mid e) .
\end{gathered}
$$

Because $\rho \in \mathcal{R}, \hat{r}_{J}$ exists (recall the properties of $\mathcal{R}$ ). Further, there exists $\hat{x} \in\left[0, v-r_{S}\right]$ such that $\min \left\{\hat{r}_{J}, v-r_{S}-x\right\} \leq$ $\rho\left(v-r_{S}-x\right)$ if $x \leq \hat{x}$ and $\min \left\{\hat{r}_{J}, v-r_{S}-x\right\} \geq \rho\left(v-r_{S}-x\right)$ if $x \geq \hat{x}$ (which again follows from the fact that $\rho \in \mathcal{R}$ ).

For any $e^{\prime}<e$,

$$
\begin{aligned}
& U\left(K, \hat{\mathbf{r}}, e^{\prime}\right)-U\left(K, \mathbf{r}, e^{\prime}\right) \\
= & \int_{0}^{v-r_{S}}\left[\rho\left(v-r_{S}-x\right)-\min \left\{\hat{r}_{J}, v-r_{S}-x\right\}\right] f\left(x \mid e^{\prime}\right) d x \\
= & \int_{0}^{\hat{x}}\left[\rho\left(v-r_{S}-x\right)-\min \left\{\hat{r}_{J}, v-r_{S}-x\right\}\right] f\left(x \mid e^{\prime}\right) d x \\
& \quad+\int_{\hat{x}}^{v-r_{S}}\left[\rho\left(v-r_{S}-x\right)-\min \left\{\hat{r}_{J}, v-r_{S}-x\right\}\right] f\left(x \mid e^{\prime}\right) d x \\
= & \int_{0}^{\hat{x}}\left[\rho\left(v-r_{S}-x\right)-\min \left\{\hat{r}_{J}, v-r_{S}-x\right\}\right] f(x \mid e)\left(\frac{f\left(x \mid e^{\prime}\right)}{f(x \mid e)}\right) d x \\
& \quad+\int_{\hat{x}}^{v-r}\left[\rho\left(v-r_{S}-x\right)-\min \left\{\hat{r}_{J}, v-r_{S}-x\right\}\right] f(x \mid e)\left(\frac{f\left(x \mid e^{\prime}\right)}{f(x \mid e)}\right) d x \\
\leq & \int_{0}^{\hat{x}}\left[\rho\left(v-r_{S}-x\right)-\min \left\{\hat{r}_{J}, v-r_{S}-x\right\}\right] f(x \mid e)\left(\frac{f\left(\hat{x} \mid e^{\prime}\right)}{f(\hat{x} \mid e)}\right) d x \\
\quad & \quad+\int_{\hat{x}}^{v-r}\left[\rho\left(v-r_{S}-x\right)-\min \left\{\hat{r}_{J}, v-r_{S}-x\right\}\right] f(x \mid e)\left(\frac{f\left(\hat{x} \mid e^{\prime}\right)}{f(\hat{x} \mid e)}\right) d x \\
= & \left(\frac{f\left(\hat{x} \mid e^{\prime}\right)}{f(\hat{x} \mid e)}\right) \int_{0}^{v-r_{S}}\left[\rho\left(v-r_{S}-x\right)-\min \left\{\hat{r}_{J}, v-r_{S}-x\right\}\right] f(x \mid e) d x \\
= & 0 .
\end{aligned}
$$

The lone inequality follows from (MLRP), and the last equality follows from (A1).

By (A1),

$$
U(K, \hat{\mathbf{r}}, e)-U(K, \mathbf{r}, e)=\int_{0}^{v-r_{S}}\left[\rho\left(v-r_{S}-x\right)-\min \left\{\hat{r}_{J}, v-r_{S}-x\right\}\right] f(x \mid e) d x=0 .
$$

Hence, for any $e^{\prime}<e$,

$$
U(K, \hat{\mathbf{r}}, e)-U\left(K, \hat{\mathbf{r}}, e^{\prime}\right) \geq U(K, \mathbf{r}, e)-U\left(K, \mathbf{r}, e^{\prime}\right) \geq 0,
$$

where the first inequality follows from (A2) and the second follows from the fact that $(K, \mathbf{r}, e)$ satisfies $(I C)$. By Step 1 , the optimal precaution $\hat{e} \in \arg \max _{\tilde{e} \in \mathbb{R}} U(K, \hat{\mathbf{r}}, \tilde{e})$ is unique. Hence, if $\hat{e}<e, U(K, \hat{\mathbf{r}}, e)<U(K, \hat{\mathbf{r}}, \hat{e})$, which would contradict (A4). We thus conclude that $\hat{e} \geq e$.

It follows from this last fact that

$$
\Pi(\hat{\mathbf{r}}, \hat{e} ; \ell)=\int_{\mathcal{X}} \pi(x, \hat{\mathbf{r}}, \ell) f(x \mid \hat{e}) d x \geq \int_{\mathcal{X}} \pi(x, \hat{\mathbf{r}}, \ell) f(x \mid e) d x=\Pi(\hat{\mathbf{r}}, e ; \ell)=\Pi(\mathbf{r}, e ; \ell) \geq K,
$$

where the first inequality holds because $\pi$ is nonincreasing in $x$ and $f$ has $(M L R P)$ in $(-x, e)$, the second equality follows from the construction of $\hat{\mathbf{r}}$, the third equality follows from (A1), and the last inequality holds because $(K, \mathbf{r}, e)$ satisfies $(I R)$. We thus conclude that $(K, \hat{\mathbf{r}}, \hat{e})$ satisfies $(I R)$.

Thus far, we have shown that $(K, \hat{\mathbf{r}}, \hat{e})$ is feasible. We now show that the firm (weakly) prefers $(K, \hat{\mathbf{r}}, \hat{e})$ to $(K, \mathbf{r}$, $e$ ), which holds because

$$
U(K, \hat{\mathbf{r}}, \hat{e}) \geq U(K, \hat{\mathbf{r}}, e)=U(K, \mathbf{r}, e),
$$

where the first inequality follows from the fact that $(K, \hat{\mathbf{r}}, \hat{e})$ satisfies $(I C)$, and the equality follows from (A3).

To prove the last statement, consider a shift from $(K, \mathbf{r}, e)$ to any $(K, \tilde{\mathbf{r}}, \tilde{e})$, where $\tilde{\mathbf{r}}=\left(\tilde{r}_{S}, \tilde{r}_{J}\right)$ is an all-debt financial contract. Suppose both are feasible, the firm prefers the shift, but, contrary to the claim, $\tilde{e}<e$. Then, because $\tilde{e}<e \leq \hat{e}$ and $(K, \tilde{\mathbf{r}}, \tilde{e})$ satisfies $(I C)$, Step 1 implies that $\tilde{r}_{S}+\tilde{r}_{J}>\hat{r}_{S}+\hat{r}_{J}$, where $\hat{\mathbf{r}}=\left(\hat{r}_{S}, \hat{r}_{J}\right)$ is defined in (A1). Observe

$$
U(K, \tilde{\mathbf{r}}, \tilde{e})<U(K, \hat{\mathbf{r}}, \tilde{e})<U(K, \hat{\mathbf{r}}, e)=U(K, \mathbf{r}, e) .
$$


The first inequality holds because $U(K, \cdot, \tilde{e})$ is strictly increasing, the second follows from the strict concavity of $U(K, \hat{\mathbf{r}}, \cdot)$ and $\tilde{e}<e \leq \hat{e}$, and the equality follows from (A3). The firm will therefore never prefer $(K, \tilde{\mathbf{r}}, \tilde{e})$ to $(K, \mathbf{r}, e)$. Because this is a contradiction, we conclude that $\tilde{e} \geq e$, as was to be shown.

Step 3. For any feasible $(K, \mathbf{r}, e)$ with all-debt structure and $r_{J}>0$, there exists a feasible senior-debt-only structure $(K, \hat{\mathbf{r}}, e)$, with $\hat{r}_{J}=0$, which the firm prefers over $(K, \mathbf{r})$. A shift to any feasible senior-debt-only structure that the firm prefers results in a (weakly) higher precaution.

Proof. Fix any feasible $(K, \mathbf{r}, e)$. Consider first a senior-debt-only structure $\mathbf{r}^{\prime}=\left(r^{\prime}{ }_{S}, 0\right)$ with $r^{\prime}{ }_{S}=r_{S}+r_{J}$. Observe for each $\tilde{e} \in \mathbb{R}_{+}$,

$$
\begin{aligned}
U\left(K, \mathbf{r}^{\prime}, \tilde{e}\right) & =K-k+\int_{0}^{v-r_{S}^{\prime}}\left(v-r_{S}^{\prime}-x\right) f(x \mid e) d x-c(\tilde{e}) \\
& =K-k+\int_{0}^{v-r_{S}-r_{J}}\left(v-r_{S}-r_{J}-x\right) f(x \mid e) d x-c(\tilde{e}) \\
& =U(K, \mathbf{r}, \tilde{e}),
\end{aligned}
$$

so $\left(\mathbf{r}^{\prime}, e\right)$ satisfies $(I C)$. Further,

$$
\pi\left(x ; \mathbf{r}^{\prime}, \ell\right)=r_{S}^{\prime}-\ell(x)=r_{S}+r_{J}-\ell(x) \geq r_{S}+\min \left\{r_{J}, z\right\}-\ell(x)=\pi(x ; \mathbf{r}, \ell) .
$$

Hence,

$$
\Pi\left(\mathbf{r}^{\prime}, e ; \ell\right)=\int_{\mathcal{X}} \pi\left(x ; \mathbf{r}^{\prime}, \ell\right) f(x \mid e) d x \geq \int_{\mathcal{X}} \pi(x ; \mathbf{r}, \ell) f(x \mid e) d x=\Pi(\mathbf{r}, e ; \ell) \geq K,
$$

proving that $\left(\mathbf{r}^{\prime}, e\right)$ satisfies $(I R)$, and is thus feasible.

Because $\Pi(\mathbf{r}, e ; \ell)$ is continuous and strictly increasing in $\mathbf{r}$, there exists a senior-debt-only structure $\hat{\mathbf{r}}=\left(\hat{r}_{S}, 0\right)$ with $\hat{r}_{S} \leq r_{S}+r_{J}$ such that

$$
\Pi(\hat{\mathbf{r}}, e ; \ell)=\Pi(\mathbf{r}, e ; \ell)
$$

Consider any $e^{\prime} \in \mathbb{R}_{+}$. Then,

$$
\begin{aligned}
& U\left(K, \hat{\mathbf{r}}, e^{\prime}\right)-U\left(K, \mathbf{r}, e^{\prime}\right) \\
= & \int_{0}^{v-\hat{r}_{S}}\left(v-\hat{r}_{S}-x\right) f\left(x \mid e^{\prime}\right) d x-\int_{0}^{v-r_{S}-r_{J}}\left(v-r_{S}-r_{J}-x\right) f\left(x \mid e^{\prime}\right) d x \\
= & \int_{0}^{v-\hat{r}_{S}} F\left(x \mid e^{\prime}\right) d x-\int_{0}^{v-r_{S}-r_{J}} F\left(x \mid e^{\prime}\right) d x \\
= & \int_{v-r_{S}-r_{J}}^{v-\hat{r}_{S}} F\left(x \mid e^{\prime}\right) d x \geq 0 .
\end{aligned}
$$

Furthermore, the last line is nondecreasing in $e^{\prime}$, which implies $\hat{e} \geq e$, where

$$
\hat{e}=\arg \max _{e^{\prime} \in \mathbb{R}_{+}} U\left(K, \hat{\mathbf{r}}, e^{\prime}\right) .
$$

Hence, $(K, \hat{\mathbf{r}}, \hat{e})$ satisfies $(I C)$. It also satisfies $(I R)$, because

$$
\Pi(\hat{\mathbf{r}}, \hat{e} ; \ell) \geq \Pi(\hat{\mathbf{r}}, e ; \ell)=\Pi(\mathbf{r}, e ; \ell) \geq K
$$

where the first inequality follows because $\Pi$ is nondecreasing in $e$, the first equality follows from (A6), and the second inequality follows from $(K, \mathbf{r}, e)$ being feasible.

Because $(K, \hat{\mathbf{r}}, \hat{e})$ is feasible, it suffices to show that the firm prefers $(K, \hat{\mathbf{r}}, \hat{e})$ to $(K, \mathbf{r}, e)$, which follows because

$$
U(K, \hat{\mathbf{r}}, \hat{e}) \geq U(K, \hat{\mathbf{r}}, e) \geq U(K, \mathbf{r}, e)
$$

where the first inequality follows from (A8), and the second follows from (A7).

To prove the last statement, consider a shift from $(K, \mathbf{r}, e)$ to any $(K, \tilde{\mathbf{r}}, \tilde{e})$, where $\tilde{\mathbf{r}}=\left(\tilde{r}_{S}, 0\right)$ is a senior-debt-only financial contract. Suppose both are feasible and the firm prefers the shift, but, contrary to the claim, $\tilde{e}<e$. Then, because $(K, \mathbf{r}, e)$ and $(K, \tilde{\mathbf{r}}, \tilde{e})$ both satisfy $(I C)$, by Step 1 , we must have $\tilde{r}_{S}>r_{S}+r_{J}$. Step 1 then further implies that

$$
U(K, \tilde{\mathbf{r}}, \tilde{e})<U(K, \mathbf{r}, e)
$$

so the firm will never $\operatorname{prefer}(K, \tilde{\mathbf{r}}, \tilde{e})$ to $(K, \mathbf{r}, e)$, a contradiction. Therefore, we conclude that $\tilde{e} \geq e$.

(C) RAND 2008 . 
Proof of Proposition 2. Lemma 1' implies that the social planner would choose the senior-debt-only structure (i.e., with $r_{J}=0$ ). (The social planner would prefer to choose a structure that induces the highest precaution from the firm.)

We next show that the social planner would choose $\ell(\cdot)=0$. To see this, fix any $(\mathbf{r}, K, e, \ell)$ that satisfies $(I C)$ and $(I R)$, where $K \in[k, v], \mathbf{r}=\left(r_{S}, 0\right)$, and $\ell(\cdot) \geq 0$. We show that there exists $(\hat{\mathbf{r}}, K, \hat{e}, \hat{\ell})$, with $\hat{\ell}(\cdot)=0$ and $\hat{e} \geq e$, satisfying $(I C)$ and $(I R)$. Further,

To this end, consider first $(\mathbf{r}, K, e, 0)$. Because this gives exactly the same payoff to the firm, it satisfies $(I C)$.

$$
\pi(x ; \mathbf{r}, 0)=r_{S} \geq r_{S}-\ell(x)=\pi(x ; \mathbf{r}, \ell) .
$$

Hence,

$$
\Pi(\mathbf{r}, e ; 0) \geq \Pi(\mathbf{r}, e ; \ell) \geq K
$$

so $(\mathbf{r}, K, e, 0)$ satisfies $(I R)$.

Hence, as before, there exists $\hat{\mathbf{r}}=\left(\hat{r}_{S}, 0\right)$ with $\hat{r}_{S} \leq r_{S}$ such that

$$
\Pi(\hat{\mathbf{r}}, e ; 0)=\Pi(\mathbf{r}, e ; \ell) .
$$

Because $\hat{r}_{S} \leq r_{S}$, the same argument as in Step 2 of Lemma 1' proves that there exists $\hat{e} \geq e$ such that $(\hat{\mathbf{r}}, K, \hat{e}, 0)$ satisfies $(I R)$ and $(I C)$. Consequently, it is optimal for the social planner to choose $\ell=0$.

Because the social planner chooses a senior-debt-only structure and imposes no liability on the lender, the social planner's choice coincides with that of the unregulated firm, except $K$. In other words, $e_{0}(K)$ is precisely the precaution level the social planner induces with the choice of $K \geq k$. Hence, the social welfare level associated with $K \geq k$ is $W(K$, $\left.e_{0}(K)\right)$. It is straightforward to check that $W\left(K, e_{0}(K)\right)$ is nonincreasing in $K$ for $K \geq k$. Hence, we conclude that $K^{*}=$ $k$ and $e^{*}=e_{0}(k)$.

\section{References}

Balkenborg, D. "How Liable Should a Lender Be? The Case of Judgment Proof Firms and Environmental Risk: Comment." American Economic Review, Vol. 91 (2001), pp. 731-738.

BEARD, T.R. "Bankruptcy and Care Choice.” RAND Journal of Economics, Vol. 21 (1990), pp. 626-634.

BebchuK, L.A. AND FrIED, J.M. "The Uneasy Case for the Priority of Secured Claims in Bankruptcy." Yale Law Journal, Vol. 105 (1996), pp. 857-934.

— AND — . "The Uneasy Case for the Priority of Secured Claims in Bankruptcy: Further Thoughts and a Reply to Critics." Cornell Law Review, Vol. 82 (1997), pp. 1279-1348.

Boyd, J. And Ingberman, D.E. "Noncompensatory Damages and Potential Insolvency.” Journal of Legal Studies, Vol. 23 (1994), pp. 895-910.

— AND _ . "Do Punitive Damages Promote Deterrence?" International Review of Law and Economics, Vol. 19 (1999), pp. 47-68.

Boyer, M. AND LAFFONT, J.-J. "Environmental Risks and Bank Liability.” European Economic Review, Vol. 41 (1997), pp. $1427-1459$

Brooks, R.R.W. "Liability and Organizational Choice.” Journal of Law and Economics, Vol. 1 (2002), pp. 91-125.

Clark, K. "How Wall Street Can Securitize Anything: On the Frontier of Creative Finance." Fortune, April 28, 1997.

Dari Mattiacci, G. And De Geest, G. “Judgment Proofness under Four Different Precaution Technologies.” Journal of Institutional and Theoretical Economics, Vol. 161 (2005), pp. 38-56.

— AND PARISI, F. “The Cost of Delegated Control: Vicarious Liability, Secondary Liability and Mandatory Insurance." International Review of Law and Economics, Vol. 23 (2003), pp. 453-475.

DeMarzo, P., Kremer, I., And Skrzypacz, A. "Bidding with Securities: Auctions and Security Design." American Economic Review, Vol. 95 (2005), pp. 936-959.

Drew, C. And Newman, A. "Taxi Owners Deftly Dodge Claims of Accident Victims.” New York Times, May 24, 1998.

Gilles, S.G. "The Judgment-Proof Society.” Washington and Lee Law Review, Vol. 63 (2006), pp. 603-715.

Hansmann, H. AND KRAakman, R.H. "The Uneasy Case for Limiting Shareholder Liability in Tort." Yale Law Journal, Vol. 100 (1991), pp. 1879-1934.

Harrell, C.E., Rice, J.L. III, ANd Shearer, W.R. "Securitization of Oil, Gas, and Other Natural Resource Assets: Emerging Financing Techniques.” Business Law, Vol. 52 (1997), pp. 885-946.

Hart, O. And Moore, J. "Debt and Seniority: An Analysis of the Role of Hard Claims in Constraining Management." American Economic Review, Vol. 85 (1995), pp. 567-585.

Hiriart, Y. AND Martimort, D. “The Benefits of Extended Liability.” RAND Journal of Economics, Vol. 37 (2006), pp. $562-582$.

INNES, R.D. "Limited Liability and Incentive Contracting with Ex-Ante Action Choices." Journal of Economic Theory, Vol. 52 (1990), pp. 45-67. 
Jensen, M.C. And Meckling, W.H. "Theory of the Firm: Managerial Behavior, Agency Costs and Ownership Structure." Journal of Financial Economics, Vol. 3 (1976), pp. 305-360.

— AND —. "How Liable Should a Lender Be? The Case of Judgment Proof Firms and Environmental Risk: Comment." American Economic Review, Vol. 91 (2001), pp. 724-730.

LoPuCKI, L.M. "The Death of Liability.” Yale Law Journal, Vol. 106 (1996), pp. 1-92.

Mandell, D.B. The Doctor's Wealth Protection Guide, . Austin, Tex: Guardian Publishing, 1999.

Modigliani, F. And Miller, M. "The Cost of Capital, Corporation Finance and the Theory of Investment." American Economic Review, Vol. 48 (1958), pp. 261-297.

Notes. "Switching Priorities: Elevating the Status of Tort Claims in Bankruptcy in Pursuit of Optimal Deterrence." Harvard Law Review, Vol. 116 (2003), pp. 2541-2564.

Perotti, E. AND SpIER, K.E. "Capital Structure as a Bargaining Tool: The Role of Leverage in Contract Renegotiation." American Economic Review, Vol. 83 (1993), pp. 1131-1141.

PITCHFORD, R. "The Role of Tort and Debt Bankruptcy Priority in a Model of Firm Precaution Choice.” In Three Essays on Contracts and Social Harm,. Ph.D. Dissertation, MIT, 1993.

—. "How Liable Should a Lender Be? The Case of Judgment Proof Firms and Environmental Risk." American Economic Review, Vol. 85 (1995), pp. 1171-1186.

Polinsky, A.M. And Shavell, S. "Punitive Damages: An Economic Analysis.” Harvard Law Review, Vol. 111 (1998), pp. 869-962.

Ringleb, A.H. And Wiggins, S.N. "Liability and Large-Scale, Long-Term Hazards." Journal of Political Economy, Vol. 98 (1990), pp. 574-595.

SHAVELL, S. “The Judgment Proof Problem.” International Review of Law and Economics, Vol. 6 (1986), pp. 45-58.

- "Minimum Asset Requirements and Compulsory Liability Insurance as Solutions to the Judgment-Proof Problem." RAND Journal of Economics, Vol. 36 (2005), pp. 63-77.

Silverman, R.W. "Litigation Boom Spurs Efforts to Shield Assets—Doctors, Executives Turn to Trusts that Are Off-Limits to Creditors." Wall Street Journal, October 14, 2003.

SPIER, K.E. AND SyKeS, A.O. "Capital Structure, Priority Rules, and the Settlement of Civil Claims.” International Review of Law and Economics, Vol. 18 (1998), pp. 187-200.

Sullivan, A., "Oil Firms, Shippers Seek to Circumvent Laws Setting No Liability Limit for Spills.” Wall Street Journal, July 26, 1990.

Summers, J.J. "The Case of the Disappearing Defendant: An Economic Analysis." University of Pennsylvania Law Review, Vol. 132 (1983), pp. 145-185.

Tirole, J. The Theory of Corporate Finance, Princeton, NJ: Princeton University Press, 2005.

Ulph, A. And Valentini, L. "Environmental Liability and the Capital Structure of Firms." Resource and Energy Economics, Vol. 26 (2004), pp. 393-410.

WARREN, E. AND WeStBRoOK, J.L. "Contracting out of Bankruptcy: An Empirical Intervention.” Harvard Law Review, Vol. 18 (2005), pp. 1197-1256. 
Copyright of RAND Journal of Economics (Blackwell) is the property of Blackwell Publishing Limited and its content may not be copied or emailed to multiple sites or posted to a listserv without the copyright holder's express written permission. However, users may print, download, or email articles for individual use. 